\title{
Nurturing an Invitational Approach to Professional Development
}

\author{
Violet Aydon-Pou \\ RTLB, Hamilton West Cluster
}

\begin{abstract}
Resource Teachers: Learning and Behaviour (RTLB) are agents of change, charged with the responsibility to facilitate paradigm shift from traditional to inclusive models of educational theory and practice. With seven years experience in an RTLB role I have come to the realisation that if there is congruence between a practitioner's value and belief system and the ethos that underpins inclusive pedagogy, the journey of change will likely be a seamless one. When there is incongruence the journey is quite often a much more difficult one; however, if successful, in terms of achieving paradigm shift, is a journey worth sharing with others.
\end{abstract}

\section{INTRODUCTION}

This is a story of paradigm shift, a celebration of commitment made by a "traditional/punitive" teacher: of re-positioning to a strengths-based orientation using an invitational approach in professional development.

An "invitation to think" versus "gifting knowledge" is considered the quintessential point of difference between constructivist and traditional models of teaching and learning (Askew \& Lodge, 2000). It is this, the "invitation to think", which has ultimately guided and shaped the professional development approach presented here.

\section{Setting}

The setting for the development of this Invitational approach to professional development is a North Island secondary school. The key player in this story is Teacher $X$, an experienced classroom practitioner who was required to teach outside Teacher $X$ 's specialist area in a core subject Year 10 class.

\section{The journey begins}

At the end of Term 2, 2007 this core subject Year 10 class was formally referred for RTLB assistance and duly allocated through the Review and Intake process. The issue identified: disruptive behaviours across two classroom contexts obstructing teaching and learning.

\section{Data gathering to needs analysis}

The RTLB, in partnership with the Year 10 Dean, held a series of separate meetings with all the teachers of this class and also with the students to gather their stories. The stories shared a common theme - disruptive behaviour impacting upon the quality of teaching and learning in two classroom settings invoking feelings of frustration, anger and despondency.

\section{Developing intervention}

The information generated from the sharing of stories was acknowledged and reframed into language that offered "possibilities". There was an invitation to both the group of teachers and class of students to visualise and describe an ideal teaching and learning lesson; and then to consider how this lesson might be co-created to occur and be sustained in a lived reality. This information served as the intervention and was called the "Treaty". The overarching goal: To create a quality teaching and learning environment where everybody can be successful.

Teacher X's class was one of the two settings identified as the place where disruptive behaviours occurred with this group of learners. Teacher $X$ was prepared to have the implementation of the intervention Treaty "monitored" in the class. Therefore the rest of this article is dedicated to Teacher X's role and experiences in this journey.

\section{Implementing intervention}

The implementation of the Treaty required the RTLB to provide in-class support, and to gather "evidence of change" in the classroom context. This occurred through:

- Cyclic classroom observations of teacher teaching and five target students' learning - once a week for a total of 16 weeks.

- Two minute interviews with the five randomly-selected target students

- Post-observation reflective conversations with the teacher - once a week

- Class-wide surveys for student feedback - twice a term.

\section{Evaluating \& refining intervention}

The Treaty served as a critical document of mutual accountability, and was always used as a point of reference when analysing information generated from the data-gathering tools listed above. As a formal agreement between students and teachers it provided a crucial pathway forward in terms of providing a space and opportunities to forge respectful relationships. For example, the Treaty required Teacher $X$ to greet the 
students with a smile, to say hello... and when they left the classroom Teacher $X$ was expected to say good bye and 'hope you have a nice day'.

For their part in the teaching and learning contract, the students made a collective commitment to 'listen to the teacher when he/she asked for their attention'; 'to adhere to the 3-strikes then time-out' for inappropriate or disruptive behaviour; to appoint time keepers whose responsibility it was to inform the teacher there was five minutes to go before the bell rang providing time for students to pack up.

Initially Teacher $X$ considered the smiling, warm greetings and farewells, to be very contrived - "I feel I'm being insincere". Nonetheless Teacher X persisted and in due course came to share with the RTLB "it no longer feels contrived...I feel good about greeting them ... and smiling because I really do look forward to teaching them".

A description of these data gathering tools and the purpose they served is presented below.

\section{Data gathering tool - classroom observations} Drawing upon the knowledge and experiences of Professor Glynn at the University of Waikato, the RTLB developed an observation tool for implementation in classroom contexts. Professor Glynn met regularly with the RTLB over a two month period to discuss the structure and format of the observation tool; consider the purpose and possible impacts of implementing this tool in classroom contexts; as well as what might be focused on and recorded.

The purpose of this tool was to capture information from the classroom environment and then to offer this data to the classroom teacher for processing. This was done within the context of a professional, reflective conversation. To address issues of judgmental and valueladen observation data, the RTLB adopted a "descriptive" approach when executing the classroom observation. The observation tool that was developed requires an observer to:

- Describe what is happening in a teaching and learning episode (55 minute lesson).

- Interview and record views about learning from five randomly selected students in the classroom.

The observation tool requires adherence to a prescribed timeframe including:

- 10 minutes for recording what is happening to set the teaching/learning scene.

- 25 minutes dedicated to recording alternating chunks of teacher teaching, and 5 target students learning.

- Two minute interviews with each of the five target students.
- Five minutes to record the closure of the teaching and learning episode.

Data gathering tool - interviews with target students Included in the design of this observational tool were two-minute timeslots for the observer to interview each of the five target students. This occurred in the final quarter of the lesson with the last five minutes dedicated to observing how the teacher closed the teaching and learning episode.

Students were invited to answer these two questions using one of the responses high/medium/low

- Would you tell me what your level of engagement in learning has been so far in this lesson?

- Would you tell me what your level of thinking has been so far in this lesson?

They were then invited to justify their responses. The RTLB posed the invitation:

- Would you like to tell me why you consider this is the level of your:

- Engagement in learning?

- Thinking?

\section{Data gathering tool - reflective learning conversations template}

Concurrent with developing the observation tool the RTLB also prepared a template to manage and capture information from the professional conversations with Teacher $X$ during the post-classroom observation. The principle of minimizing observer influence was paramount when developing this template. This template was constructed according to the following $5 \mathrm{x}$ " $\mathrm{A}$ " format:

Artefact: In the context of this story, the artefact used was usually the classroom observation. In one session a video clip of students involved in a cooperative learning task served as the artefact. An artefact creates an opportunity to engage in professional conversations.

Analysis - The teacher is invited to think about and draw meanings from the information contained in the artefact, in this case the observation sheet. In the initial meetings, the RTLB used two key questions to initiate the analysis phase. The teacher is asked whether they consider the 'described teaching acts' recorded on the observation sheet were:

- Examples of invitations to learners to think or,

- Examples of the teacher gifting knowledge.

Acknowledgements - An opportunity for the teacher to acknowledge to themself variables that might be considered when reading/reflecting upon the observation data. For example, one of the variables was a target student returning to class after a week's absence which led to Teacher $\mathrm{X}$ offering a copy of the teaching notes. 
Advice - An invitation to the teacher to offer themself advice. Knighton's (2007) work in the area of teacher feedback shaped this section.

In this work precedence is placed on teacher strengths and capacity to bring meanings and understandings to their own lived experiences. That is to say the teacher has first-rights to name his/her "acknowledgements" and first-rights to proffer "advice" to themselves reflecting a strengths-based orientation wherein a safe and respectful space is provided for individuals to "name" their circumstances, their struggles, their experiences, themselves. The power to name one's owned lived reality, including one's "self", one's situation and condition, is 'the beginning of real empowerment' (Saleebey, 1996, p.303).

Action: The teacher is invited to consider how the advice proffered to self might be put into action.

The RTLB discreetly used the " $5 A$ " framework by writing "AAAAA" across the top of a blank page. As both progressed through each aspect the correlating "A" was simply marked off. In this way, the recording of information generated from the professional conversations was "free-flow", uninterrupted and unconstrained by a "boxed" style template.

\section{Refining Treaty intervention}

As Teacher $\mathrm{X}$ became more competent in working within the parameters of the "Treaty", "value" was added to the intervention. For example, to manage student behaviours, the focus was upon celebrating strengths and capabilities. Drawing upon the " 3 strikes and out" strategy Teacher $X$ created the " 3 strikes and in for a reward" every 15 minutes saying, 'I'm going to check that everyone is on task and if you are then you each get a reward tick'. The fact that Teacher $X$ was open and transparent in the process, coupled with the fact everyone had the opportunity to be engaged when checked, meant every student could earn their reward points.

\section{OUTCOMES}

There were a number of shifts and changes noted in this particular classroom setting including greater responsibility taken by the teacher to remove barriers to success for all of the students in the class. For example, Teacher $X$ offered students who had missed the previous lesson, the lesson plan in hardcopy format. For those students who had been "identified" in the $5 \mathrm{~A}$ meeting as having special needs, Teacher $X$ would spend extra in time working alongside of them. The RTLB noted through classroom observations, that Teacher $\mathrm{X}$ increasingly engaged in conversations with students in an "alongside of" position - in other words either crouching down to their eye level or, if a spare chair was available, sitting down at the desk next to them.
Journey One concluded with an in-class celebration with Teacher $X$, the students and the RTLB. Students had bought a box of chocolates for all to share, and formally acknowledged the changes that had been made by their teacher. Teacher $X$ had been one of two teachers identified by students as being "difficult" and "uncaring". The fact that Teacher $X$ had been prepared to consider "other ways" of teaching bespeaks a person of courage and commitment, a practitioner who positioned themself within an ethic of care.

\section{CONCLUSION}

The catalyst for achieving change in this context was Teacher X's commitment to "reinvent" themself to meet the demands of a 'new [cultural] environment' (Teacher X, personal communication, 2009). As a story of "reinvention" this article speaks to an experienced "traditional/punitive" orientated teacher shifting to a collaborative model of teaching, to the creation of "relational" classroom environments imbued with an ethic of care and respect (Noddings, 1982, 1984, 1986). It is a story of teacher and students achieving agency, an acknowledgement and celebration of strengths and capabilities wherein acts of co-construction invited a future of possibilities.

The RTLB asked that this article close with a quote from Teacher X:

I used to have power as a punitive teacher - I had developed sophisticated techniques as a punitive teacher - but this didn't work in this school... [now] I have learnt how to use positive approaches... I don't want to go back...I think it is more healthy to use positive approaches...once you have a strategy that works you want to make the strategy even better... more elaborate... sophisticated... .

(Extract from Journal capturing Teacher X \& RTLB professional conversations, 2007)

\section{REFERENCES}

Askew, S., \& Lodge, C. (2000). 'Gifts, ping-pong and loops linking feedback and learning. In S. Askew (Ed) Feedback for Learning (pp1 - 17). London: RoutledgeFalmer

Knighton, K. (2007). Bringing out the best in teachers. Leaders for Learning Conference. Notes from conference at New Zealand Graduate School of Education.

Noddings, $\mathrm{N}$ (1984). Caring: A feminine approach to ethics and moral education. Berkley: University of California Press

Noddings, N (1986). Fidelity in teaching, teacher education and research in teaching. Harvard Educational Review, 5, (4) 490-510

Noddings, $\mathrm{N}$ (1982). The challenge to care in schools. New York: Teachers' College Press 
Saleebey, D. The strengths perspective in social work practice: extensions and cautions. Social Work.

May 1996; 41, 3: Academic Research Library.

Other:

Email from Teacher $X$ to RTLB (2009). Reflective feedback on this article as work in progress.

Professional Development Journal containing information drawn from conversations between RTLB \& Teacher X in 2007.

\section{AUTHOR PROFILE}

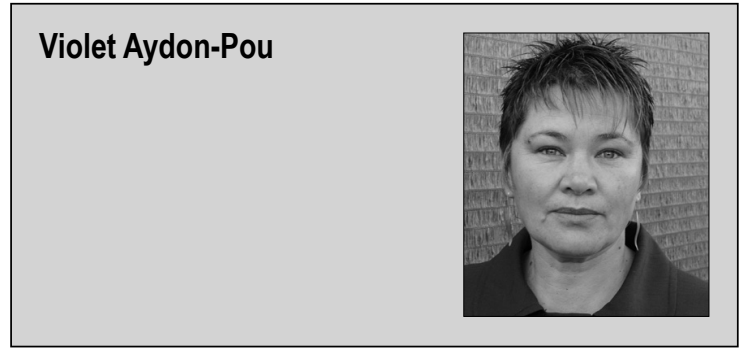

\section{Violet Aydon-Pou}

My name is Violet Aydon-Pou, an RTLB working in the Hamilton West Cluster. I entered the service in when I won a position in the Matamata Schools Cluster. In 2005, with a teachers study award, I completed my M.A. with a literacy research study 'Rangiwai'. This year I won one of the RTLB Association inaugural study awards. My proposed course in 2010 is to begin developing an educational model of supervision as a Doctoral study.

In preparing my application for the RTLB Association study award I drew extensively upon my work experiences with a seasoned teacher and his students. This article speaks to the first cycle of these experiences. 